\title{
Methodology Development to Locate Hydrogen Stations for the Initial Deployment Stage
}

\author{
Kenshi Itaoka ${ }^{1, *}$, Seiichiro Kimura ${ }^{1}$, and Katsuhiko Hirose ${ }^{1}$ \\ ${ }^{1}$ Kyushu University, 744 Motooka, Nishi-ku, Fukuoka 819-0395, Japan
}

\begin{abstract}
Hydrogen station deployment needs to be progressed in response to the introduction of fuel cell vehicles (FCVs) to the commercial market. Since resources allocated for deployment are limited for either private companies who wish to install stations and governments who provide subsidies, efficient station allocation should be cognizant of the service of potential customers. Based on a literature review, the results of a social survey and data analysis, p-median is chosen to find optimum locations for hydrogen stations. Location and the amount on potential demand for FCV's in the early stage of deployment is estimated by a regression model. The result of GIS analysis for both 2020 and 2025 using p-median implies the importance of covering regional hub cities (such as prefectural capital cities) as well as metropolises. The coverage rate of potential FCV demand is around $60 \%$ at the national level, and exceeds 70 to 80 percent when limited to urban areas for the 400 -station allocation. The geographical tendency of station locations allocated by the developed methodology provides guidance for hydrogen station location practice.
\end{abstract}

\section{Introduction}

In response to the introduction of fuel cell vehicles (FCVs) in the commercial market in 2015, the development of hydrogen station networks has been progressed in recent years in Japan. The Ministry of Economy, Trade and Industry (METI) issued the Strategic Roadmap for Hydrogen and Fuel Cells in 2014 (revised in 2016) [1] and identified a need for strategic development of hydrogen stations. While the Roadmap did not refer to a specific plan for such development, estimates based on current progress on hydrogen station construction indicate a certain shortage of ST, especially in urban areas.

Installing a hydrogen refueling station is much more expensive than installing a gas station. The initial investment for a hydrogen station is more than 4 hundred million yen. Not only private companies wish to locate hydrogen stations, but also governments provide subsidies to those companies which need to pay a lot of money for hydrogen station deployment. The more hydrogen stations are installed, the more convenient FCV infrastructure will be. However, resources to be allocated to hydrogen station deployment are limited because the business to run a hydrogen station is not profitable in the early stage of FCV deployment and governments have an uncountable number of policies which need to be budgeted. It is thus necessary to allocate stations efficiently to serve potential

\footnotetext{
* Corresponding author: k.itaoka@i2cner.kyushu-u.ac.jp
} 
customers.

The key objective of this study is to develop a model to allocate hydrogen infrastructure both within and outside of Japan, so as to provide implications for efficient locations of hydrogen stations in the future.

\section{Literature on Methods to Allocate Refueling Facilities}

A number of studies on the methods to optimally allocate refueling facilities have been conducted since late last century, the majority of which were initiated by researchers in the United States. Established models for refueling-facility location planning can be categorized into the following two major types: (1) location-allocation (LA) solutions; and (2) flow-demand solutions.

The LA theory was originally proposed by Cooper [2] and has been applied to refueling facility planning since late $20^{\text {th }}$ century. An LA problem is to locate a set of new facilities such that the distance from facilities to customers is minimized and an optimal number of facilities is placed in an area of interest while satisfying customer needs. For solving LA problems, numerous algorithms have been designed including $p$-median methods. The $p$-median method aims to find optimum locations of $p$ facilities such that the total sum of the distances between each customer $(i)$ and the nearest facility $(j)$ is minimized. This method is based on the assumption that automotive users prefer to refuel near their home and that a single-purpose trip is made between the customer and the facility to satisfy demand.

This method was applied to some case studies conducted to allocate hydrogen stations in the State of California [3] [4]. It was also used in a series of studies to evaluate scenarios for deploying hydrogen fueled vehicles and supporting infrastructure conducted under the direction of the USA Department of Transport, in response of the requirements of the Energy Policy Act 2005 and recommendations made in the report "The Hydrogen Economy (2004)" prepared by the National Academy of Science.

The $p$-median method has also been applied with some modifications. For example, Lin et al. developed the 'fuel-travel-back' approach,' based on $p$-median model, and applied it to derive an optimal station roll-out scheme for Southern California (i.e. to investigate how to effectively locate a limited number of hydrogen stations in an early stage of hydrogen-fueled vehicle market) [5]. The 'fuel travel-back' approach uses nodes weighted by the quantity of fuel consumed on segments "pointing to" demand node (i) (instead of population) and with travel time between demand nodes $(i)$ and candidate facility locations (j) substituted for distance.

All $p$-median based methods share a common feature of relatively simple and limited data requirements. The original $p$-median method requires data on customer locations and road networks only. The aforementioned 'fuel travel-back' approach uses data on spatial distribution of vehicle-miles traveled (instead of population), considering any point along road networks as a possible origin of a refueling trip. When the total travel time is minimized for all fuel (in gallon-minutes), the average refueling travel time is theoretically considered to be minimized.

The other type of solution, flow-demand solutions, analyzes refueling demands based on traffic flows. Hodgson argued that for many types of facilities, such as refueling facilities, convenience stores, automated teller machines, traffic flows exert a demand [6]. The unit of demand to be covered is, therefore, the path from an origin to a destination rather than considering demand as a set of nodes. This means that refueling should be assumed often as a secondary purpose of travel: customers tend to refuel on the way to somewhere else rather than making a single purpose trip solely to refuel their vehicles. Flow-demand solutions were considered to provide a behaviorally more realistic basis for 
locating refueling facilities.

There are several methods developed to solve flow-demand problems. They can be classified into three methods: Traffic count method; Flow-Capturing Location Model (FCLM) or Flow Intercepting Location Model (FILM); and Flow Refueling Location Model (FRLM).

The traffic count method is to locate stations on high-traffic routes or within high-traffic areas. For example, roads with more than certain traffic volume (e.g. $\geq 20,000$ traffic volume per day) are chosen to locate refueling facilities [7]. When refueling facilities are to be located in high-traffic areas, the total sum of vehicle kilometers traveled is calculated for each area unit and refueling facilities are located where a certain level of vehicle kilometers traveled is achieved [8]. This method is relatively simple yet has some shortfalls such as the double-counting issue. It is possible to count the same trips by the same drivers more than once if the trip travels multiple links, even though drivers might refuel only once, thus resulting in concentrating refueling facilities on several adjacent links of a high-volume major route (e.g. freeway).

Flow capturing methods such as FILM or FCLM were developed to avoid such double counting issues. FILM/FCLM locates a given number $(p)$ of refueling facilities so as to maximize the total possible flows that are intercepted during their travel. Basic units of demand are flows on paths across a transportation network and the flows over the network arcs are explicitly considered. Flows are captured by various methods: some studies consider a refueling facility captures a flow only when the facility is directly on the path of the flow while others consider trips are captured by the facility even when these trips require minor detours to get to the facility. FILM/FCLM tends to capture more origin-destination (OD) flows on the shortest paths between OD pairs, however, for longer inter-city trips, one refueling facility anywhere along the path may not be enough to enable a vehicle with a limited driving range to complete the trip without running out of fuel.

Lim and Kuby further advanced FILM/FCLM to FRLM to maximize the number of trips that can potentially be refueled by $p$ refueling facilities. Unlike FILM/FCLM, OD flows are covered by a combination of facilities rather than individual facilities [9]. FRLM counts a flow as refueled only if a combination of stations exists on a path that can successfully refuel the round trip between the origin and destination. At the metropolitan scale, if no round trips are longer than the assumed vehicle driving range, the FRLM reduces to the FILM/FCLM.

All FILM/FCLM/FRLM requires, in general, a matrix of OD flows, each of which must then be assigned to a particular likely path through the network. Such data are hard to work with and are not always available for all regions or scales required for analysis. Further, there are infinite number of OD pairs in reality, thus only simplified OD matrixes can be used.

\section{Analytical Method}

\subsection{Targeting potential FCV customers}

According to the diffusion of innovation theory proposed by Rogers [10], proactive adopters of any new innovations or ideas, who are categorized as "Innovators," appear at early stages of the diffusion. His theory presented that a key to successful new market development is to approach Innovators. We do not discuss whether Rogers' diffusion of innovation theory is applicable to FCVs in this paper, however it can be assumed that early customers of FCVs are not likely to be general citizens. It is thus critical to identify the features and locations of the Innovators in the FCV market. 
The revised Strategic Roadmap for Hydrogen and Fuel Cells [1] set targets for the dissemination of FCVs as follows: approximately 40,000, 200,000 and 800,000 vehicles by 2020, 2025 and 2030, respectively. This means that the main FCV customer segments are still likely to be Innovators or Early Adaptors even around 2025, therefore a targeting approach will be required for successful dissemination.

An obvious feature of FCV in the commercial market is its price. The price of FCV is more than five (5) million Japanese yen before 2020 even with government subsidies. This price level is expected to be similar until 2020. Except for the driving components and fuel of the FCV, the new FCVs introduced in the market belong to the category of traditional luxury passenger cars. We consider potential customers, Innovators or Early Adaptors for FCV, are a part of luxury passenger car customers. For 2025, middle-class automotive buyers were assumed to be FCV potential buyers as the cost reduction of FCV car to around three (3) million yen; the same price level of popular hybrid cars such as the Prius, as expected according to communication with automobile companies.

\subsection{Optimization method of location allocation of hydrogen stations}

\subsubsection{Reasoning of methodology choice}

Our study team conducted a survey research on the daily refueling behaviors of existing automotive users in March $2016(\mathrm{~N}=3,790)$. Respondents are randomly chosen from an Internet panel representing the general public who have a driver's license. The survey result shows that $71 \%$ of the respondents use refueling stations near their home while the remaining respondents prefer refueling stations along or near the routes between their home and their key driving destinations such as work places or shopping centers (Figure 1). The survey also asked travel time to the refueling stations usually used for respondents. The respondents showed the tendency to use five minutes intervals for their answer but we can see a rough tendency of proximity to the preferred refueling stations. The mean and the mode travel time to the refueling stations usually used for respondents are 9.5 minutes and five minutes, respectively (Figure 2). It should also be noted that more than $20 \%$ respondents travel over 15 minutes.

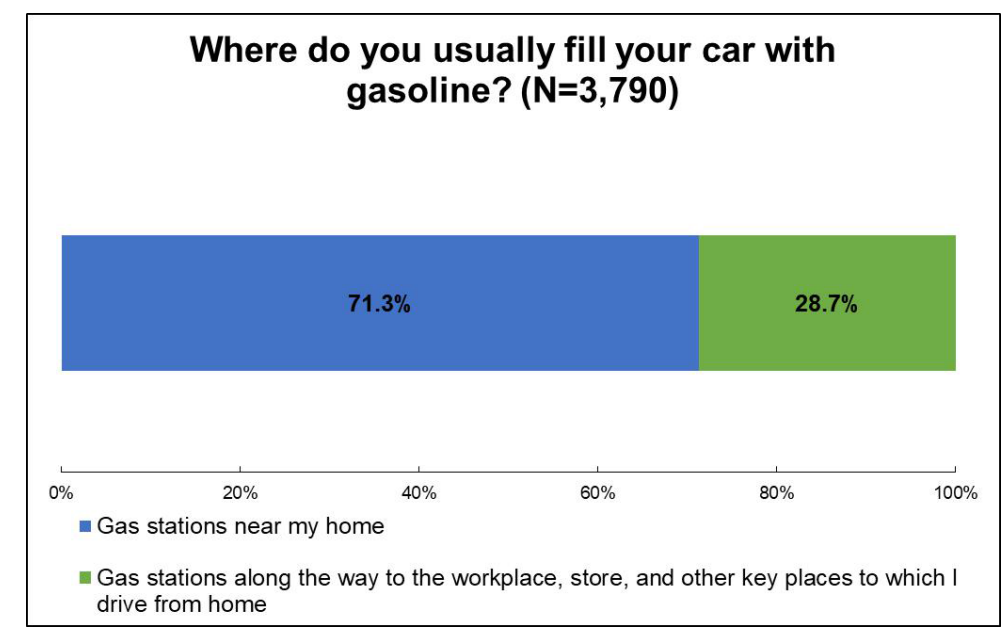

Fig. 1. Locations of gas stations where customers usually refuel 


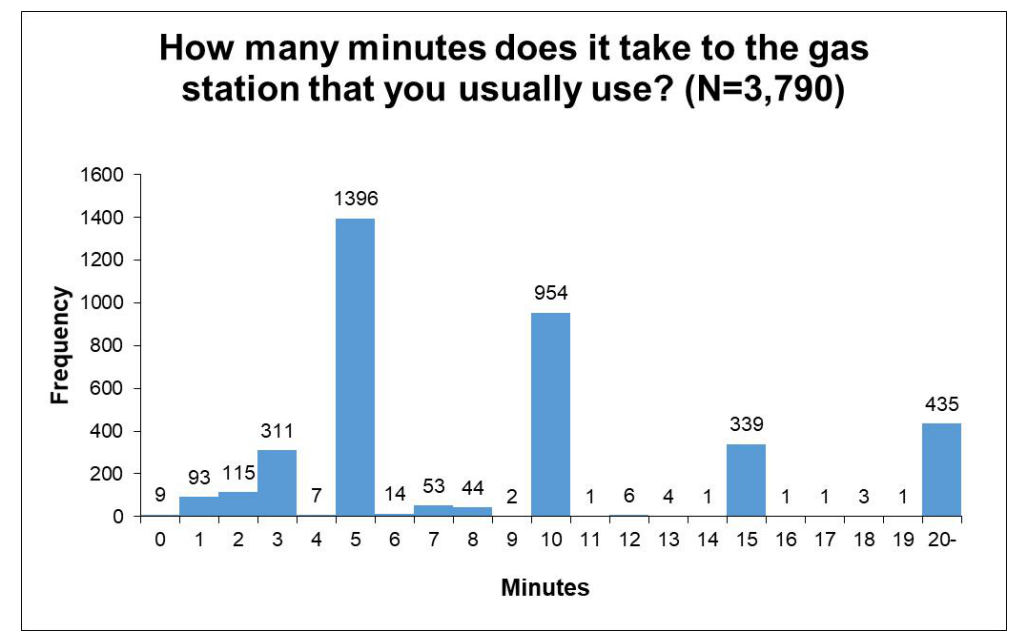

Fig. 2. Time spent at gas stations where customers usually refuel

\subsubsection{Choice of optimization method of location allocation of hydrogen stations}

We decided not to use the flow-demand solution model but P-median for optimizing geological locations of future hydrogen stations for the following reasons:

- The majority of current car users refuel their cars near their residence or office and the majority of trips users make are short distance. These imply proximity to stations is important for station location allocation, although car users do not necessarily show a strong priority toward proximity.

- The required level of geological resolution for station location cannot be obtained by flow-demand solution models but by P-median model. Only simplified OD matrixes such as intercity level OD matrixes are available for conducting flow capturing analyses. This means flow-demand solutions using such OD matrixes do not provide detailed locations within a city, yet the largest portion of car trips happen within cities in Japan.

Meanwhile, we realize that flow-demand solution models need to be used as a supplementary approach for determining the station locations to cater for mid-to-long distance trips.

\subsection{Location estimation of potential customers of FCV}

In order to identify the location and quantity of potential FCV customers with reasonable geographical resolution which is a $1 \mathrm{~km}$ square grid, car sales data at the municipal level was used to conduct regression analyses.

Stepwise regression analysis was carried out, using the data of luxury car sales at the municipal level as a dependent variable and variables of general statistics including more than fifty candidate variables as independent variables, giving consideration to multi-collinearity. The regression model should not use intercept in the equation because an existence of intercept in the model equation means the existence of some amount of potential customers automatically in every $1 \mathrm{~km}$ grid. The model fit and regression coefficients of the luxury car regression model are presented in Table 1 and Table 2, respectively.

The adjusted R-Square of 0.909 indicates a good model fit for the chosen regression 
model (see Table 1). The stepwise regression process finally leaves two explanatory variables, number of employees and total consumer spending. The variable of number of employees that is the sum of the number of people employed in the area is considered to represent demand of corporate customers and the total consumer spending is considered to represent the demand of private customers. The standardized coefficients of explanatory variables, which is 0.625 for the number of employees and 0.374 for the total consumer spending (see Table 4), indicate the corporate demand explained more than $60 \%$ to the total luxury car demand reflecting real luxury car sales statics.

Table 1. Model fit of the luxury vehicle regression model

\begin{tabular}{|r|r|r|c|}
\hline \multicolumn{1}{|c|}{$\mathrm{R}$} & \multicolumn{1}{|c|}{ R Square* $^{*}$} & $\begin{array}{c}\text { Adjusted R } \\
\text { Square }\end{array}$ & $\begin{array}{c}\text { Std. Error of } \\
\text { the Estimate }\end{array}$ \\
\hline .953 & .909 & .908 & 16.790 \\
\hline
\end{tabular}

Note: * For regression through the origin (models without an intercept), R-squared measures the proportion of variability in the dependent variable regarding the origin explained by regression

Table 2. Regression coefficients of the luxury vehicle regression model

\begin{tabular}{|l|r|r|r|r|r|}
\hline & \multicolumn{2}{|c|}{$\begin{array}{c}\text { Unstandardized } \\
\text { Coefficients }\end{array}$} & $\begin{array}{c}\text { Standardized } \\
\text { Coefficients }\end{array}$ & \multirow{2}{*}{ t } & \multirow{2}{*}{ Sig. } \\
\cline { 2 - 4 } & \multicolumn{1}{c|}{ B } & Std. Error & \multicolumn{1}{c|}{ Beta } & \multicolumn{1}{c|}{ t } \\
\hline Employees & .0004 & .000 & .625 & 44.360 & .000 \\
\hline $\begin{array}{l}\text { Total } \\
\text { consumer } \\
\text { spending }\end{array}$ & $1.206 \mathrm{E}-07$ & .000 & .374 & 26.559 & .000 \\
\hline
\end{tabular}

Similarly, a stepwise regression analysis was conducted using the car sales data at municipal level as well as general statistics, to estimate middle-class automotive demands in three dimensional geometry. The dependent valuable used in the calculation is the sales data of automobiles in the middle-class and higher price range. The model fit and regression coefficients of the middle-class automobile regression model are presented in Table 3 and Table 4, respectively.

As presented in Table 3, the adjusted R-Square is 0.935, i.e. the model fit is high. The independent variables that stepwise regression process decide in this model are the number of workers and number of employees. The number of workers that means the sum of the number people engaged in work in households within the area is considered to represent the volume of the private customer demand while the number of employees is considered to represent the demand of business customers (see Table 4). Although potential buyers of middle-class automobiles include corporate customers, private customers are the majority, which is reflected in the standardized coefficients and thus in the modelling result. For the luxury car market model, the coefficient of expenditures (i.e. income) explained the demand of private customers. However, the number of workers rather than expenditure can explain the demand of private customers in the middle-class automobile market model.

Table 3. Model fit of the mid-range vehicles (automobiles priced above the mid-range) regression model

\begin{tabular}{|r|r|r|r|}
\hline \multicolumn{1}{|c|}{ R } & R Square* & \multicolumn{1}{c|}{$\begin{array}{c}\text { Adjusted R } \\
\text { Square }\end{array}$} & $\begin{array}{c}\text { Std. Error of } \\
\text { the Estimate }\end{array}$ \\
\hline .967 & .935 & .935 & 218.090 \\
\hline
\end{tabular}

Note: * For regression through the origin (models without an intercept), R-squared measures the proportion of variability in the dependent variable regarding the origin explained by regression 
Table 4. Regression coefficients of the mid-range vehicles (automobiles priced above the mid-range) regression model

\begin{tabular}{|l|r|r|r|r|r|}
\hline & \multicolumn{2}{|c|}{$\begin{array}{c}\text { Unstandardized } \\
\text { Coefficients }\end{array}$} & $\begin{array}{c}\text { Standardized } \\
\text { Coefficients }\end{array}$ & \multirow{2}{*}{} & \multirow{2}{*}{ Sig. } \\
\cline { 2 - 4 } & \multicolumn{1}{|c|}{$\mathrm{B}$} & Std. Error & \multicolumn{1}{c|}{ Beta } & \multicolumn{1}{c|}{$\mathrm{t}$} & \multicolumn{1}{c|}{ Sig } \\
\hline Workers & .0118 & .000 & .903 & 81.611 & .000 \\
\hline Employees & .0008 & .000 & .080 & 7.241 & .000 \\
\hline
\end{tabular}

\subsection{Application of P-median to location allocation of hydrogen stations}

The p-median problem is a type of discrete location model which places "p" facilities in a manner to minimize the sum of the demand-weighted distance between a demand node and the closest facility. In this study, we aimed to optimize the facility locations, when placing a given number of hydrogen stations (ST) within a defined area, by minimizing the total travel time cost (i.e. the sum of the potential demand node multiplied by time distance). The algorithm of the calculation is presented below:

The total distances between all users and the closest ST $\left(r_{i j}\right)$, is expressed in the following equation:

$$
r_{i j}=f\left(x_{i}, y_{i}\right) d_{i j}
$$

where:

$\mathrm{a}_{i}\left(\mathrm{x}_{i}, \mathrm{y}_{i}\right)$ : a given demand node

$\mathrm{f}\left(\mathrm{x}_{i}, \mathrm{y}_{i}\right)$ : location of a user

$\mathrm{d}_{i j}$ : distance between a user $\mathrm{f}\left(\mathrm{x}_{i}, \mathrm{y}_{i}\right)$ and the closest $\mathrm{ST}\left(\mathrm{s}_{j}\right)$

The distance $\left(t_{j}\right)$ between a given ST $\left(\mathrm{s}_{j}\right)$ and demand nodes $(1,2, \cdots, \mathrm{j}, \cdots, \mathrm{m})$ within the ST's coverage is then calculated using Equation 2:

$$
t_{j}=\sum_{i=1}^{m} r_{i j}=\sum_{i=1}^{m} f\left(x_{i}, y_{i}\right) d_{i j}
$$

Therefore, When the number of ST to be placed is "N," the sum ( $\left.\boldsymbol{T}_{\text {total }}\right)$ of the distances between demand nodes and the closest STs

When the total number of ST users in all defined areas are set as $\mathrm{N}_{h}$, the average distance to the closest ST is expressed in Equation 3:

$$
T_{\text {avg }}=\frac{1}{N_{h}} T_{\text {total }}=\frac{1}{N_{h}} \sum_{j=1}^{N} \sum_{i=1}^{m} f\left(x_{i}, y_{i}\right) d_{i j}
$$

The objective function is set to minimize the average travel distance $\left(T_{\text {avg }}\right)$. Equation 4 is then used to identify a ST location $\left(\mathrm{s}_{j}\right)$ :

$$
T_{\text {avg }}^{\min }=\min _{S} \frac{1}{N_{h}} \sum_{j=1}^{N} \sum_{i=1}^{m} f\left(x_{i}, y_{i}\right) d_{i j}
$$

As $\mathrm{N}_{h}$ is a constant factor, Equation 4 can be simplified as Equation (5): 


$$
T_{a v g}^{\min }=\min _{S} \sum_{j=1}^{N} \sum_{i=1}^{m} f\left(x_{i}, y_{i}\right) d_{i j}
$$

In this model, existing STs are treated as mandatory locations, thus the number of existing ST locations $\left(\mathrm{O}=\left\{\mathrm{o}_{\mathrm{k}} \mid \mathrm{k}=1,2, \cdots, 0\right\}\right)$ is deducted from the total number of candidate ST location $\left(\mathrm{P}=\left\{\mathrm{p}_{i} \mid \mathrm{i}=1,2, \cdots, \mathrm{L}\right\}\right)$ prior to running the model. Then, the calculation using Equation (3) was repeated for all possible sets of $\mathrm{N}$ in order to determine the optimum locations of new STs. This method is a combinational optimization procedure where $\mathrm{N}$ is selected from L-O. It is impossible to validate all possible combinations in reality as the number of possible combinations is massive. Therefore, we applied heuristics to this model in order to identify a result close enough to the optimum value and used three methods, randomized greedy algorithms [11]; vertex substitution heuristic [12]; and path relinking method [13]. Combinations of several heuristics are applied to enhance the solution accuracy. The optimum solution applying heuristics was calculated in the following procedures:

Step 1: Calculate the initial solution using randomized greedy algorithms, by which the initial solution is semi-randomized.

Step 2: Calculate a second solution applying the solution set obtained by Step 1 to vertex substitution heuristic.

Step 3: Calculate another second solution applying the solution set obtained by Step 1 except for solution set obtained by Step 2 to path relinking meta heuristics.

Step 4: Choose a more suitable solution between the two solutions identified through Steps 2 and 3.

Step 5: Repeat Steps 1 to 4 in a given number then choose the best optimal answer within identified candidate locations.

\section{Analyses and discussion}

\subsection{Locating hydrogen stations for 2020 and 2025}

The price of FVCs is likely to maintain the 2016 level until the mid-2020's although a gradual fall is anticipated in the future. As mentioned in Section 1.1, METI's Strategic Roadmap for Hydrogen and Fuel Cells estimated the number of hydrogen refueling stations in Japan to be 160 in 2020 and not to exceed 200 in the next five years. Therefore, the key FCV purchasers in 2020 are assumed to be potential luxury car buyer groups and the number of hydrogen station to be 200 in order to analyze the optimum facility locations using p-median problem.

The FCV price is expected to be lower to around three million yen by 2025 while the number of hydrogen station to increase to 320, according to the METI Roadmap. Regarding the station location analysis for 2025, the FVC purchaser group is thus assumed to be potential middle-class automobile buyer groups and the number of hydrogen station to be 400. As 92 stations are already at either the design, construction or operational stages as of the end of August 2016, the p-median analysis was conducted for the remaining 108 or 308 stations. The coverage of each station is set to be 15 minutes driving distance in rush hours for coverage analyses in the later section. The results of the optimum placement analyses are shown in Figures 3 to 7.

The results for both 2020 and 2025 indicate that hydrogen stations should be spread across the country to capture potential FCV customers effectively and to promote FCVs. Figures 3 illustrates that 94 percent prefectural capital cities are covered by the placement 
of the 200-station by 2020 and fully covered by the 400 -station allocation of 2025 . This result identified the importance of covering regional hub cities (such as prefectural capital cities) as well as metropolises such as Tokyo, Nagoya and Osaka for capturing more potential FCV customers.

Furthermore, the results for 2020 indicated that 43 out of 108 new stations are to be placed outside of four (4) major metropolitan areas (i.e. Tokyo, Kanagawa, Saitama, Chiba, Osaka, Kyoto, Hyogo, Aichi and Fukuoka). As 19 of the exiting 92 stations have been placed outside of the four (4) metropolitan areas, approximately 30 percent of the total 200 stations need to be located outside of the metropolitan areas in order to capture more potential luxury car buyers. Likewise, 163 out of 308 new stations to be built by 2025 needs to be placed in the areas other than the metropolitan areas to optimize the capture of potential middle-class automotive purchasers. This means approximately over $40 \%$ of the total 400 stations needs to be placed outside of the four metropolitan areas to optimize the potential of FCV dissemination.

Figures 3 to 7 show that most of the 200 hydrogen stations are allocated to the central urban areas and other densely populated areas within the four major metropolitan areas and not many are placed in the corridors between those cities. However, the development of hydrogen stations in such gap areas is likely to be progressed during the 400-station placement. In other words, populated areas should be covered first to maximize capture of demand when the hydrogen station number is limited to 200. The corridors between major cities and the regional centers are recommended to be covered when the station number is increased to 400 .

In reality, extra 200 stations will be added after completing the development of the first 200 stations when 400 stations are determined to be constructed in total. This study assumed different FCV prices, thus different target buyers (i.e. potential luxury car buyers for the allocation of 200 stations and potential middle-class vehicle buyers for 400 stations), for nominated years. Therefore, it is possible that some of the facility locations identified through the 200 station allocation analysis might not be identified in the 400 station allocation analysis. However, the result indicates no municipality where stations identified in the allocation of 200 stations are eliminated in the 400 station allocation.

The analysis results highlighted the importance of placing hydrogen stations in regional hub cities at a relatively early stage. It has also been confirmed that the hydrogen stations allocated to capture the needs of luxury car purchasers are unlikely to be redundant when the market is expanded to include middle-class automobile purchasers. 


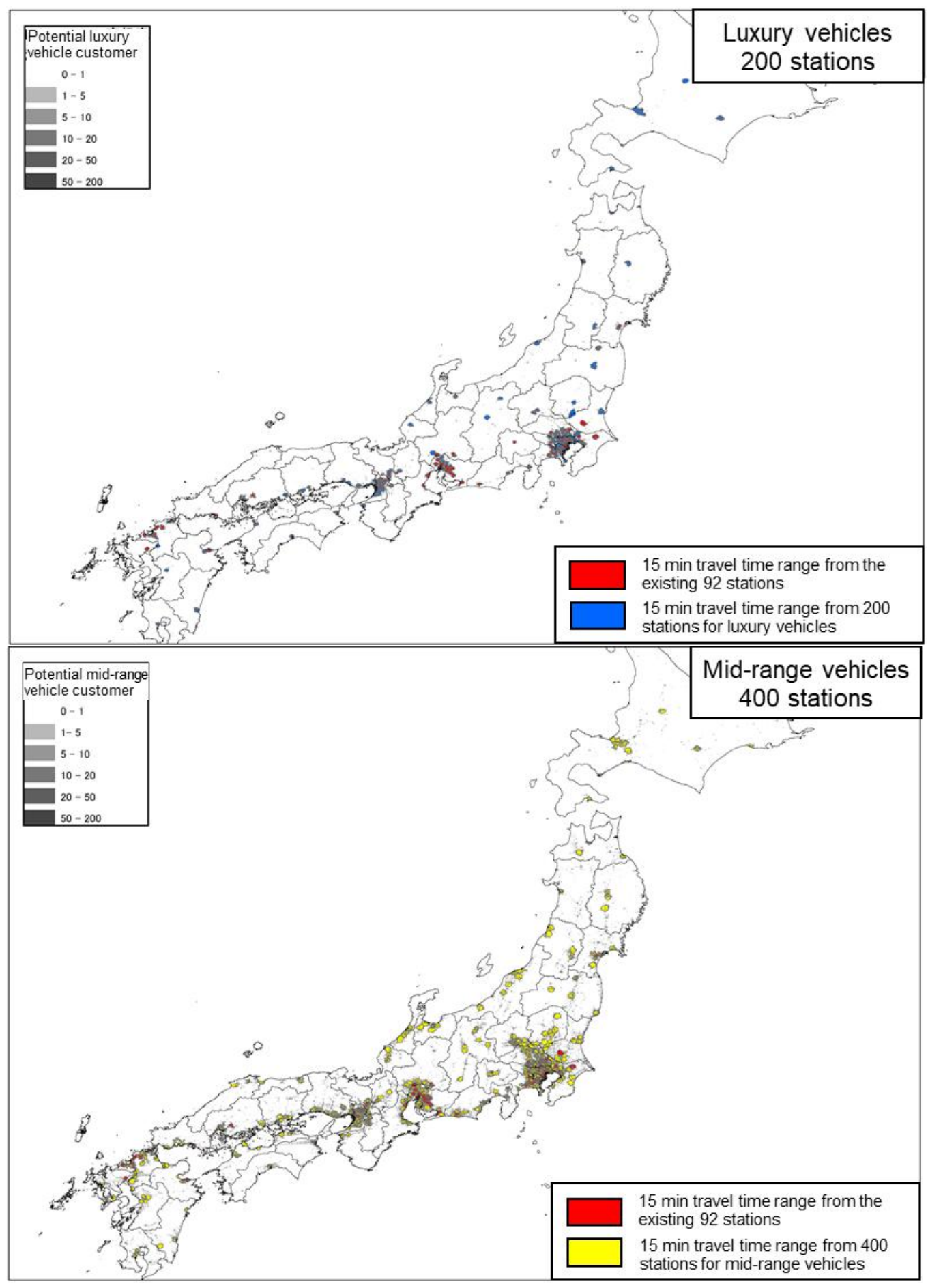

Fig. 3. Nationwide placement of 200 hydrogen refueling stations (top), 400 stations (below) (15-minute travel time range from the hydrogen refueling station shown) 


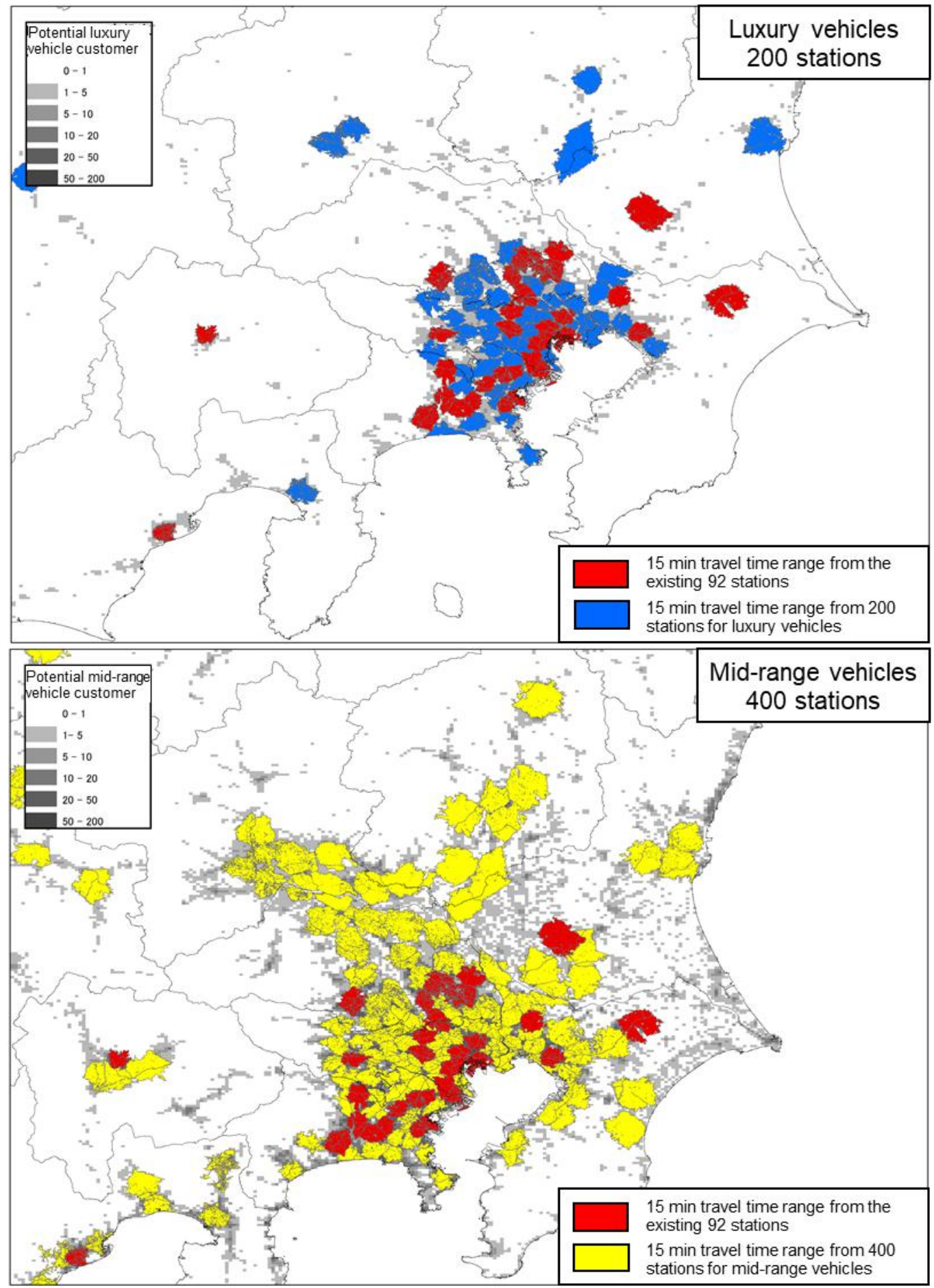

Fig. 4. Placement of 200 hydrogen refueling stations (top), 400 stations (below) in the Greater Tokyo area (15-minute travel time range from the hydrogen refueling station shown) 


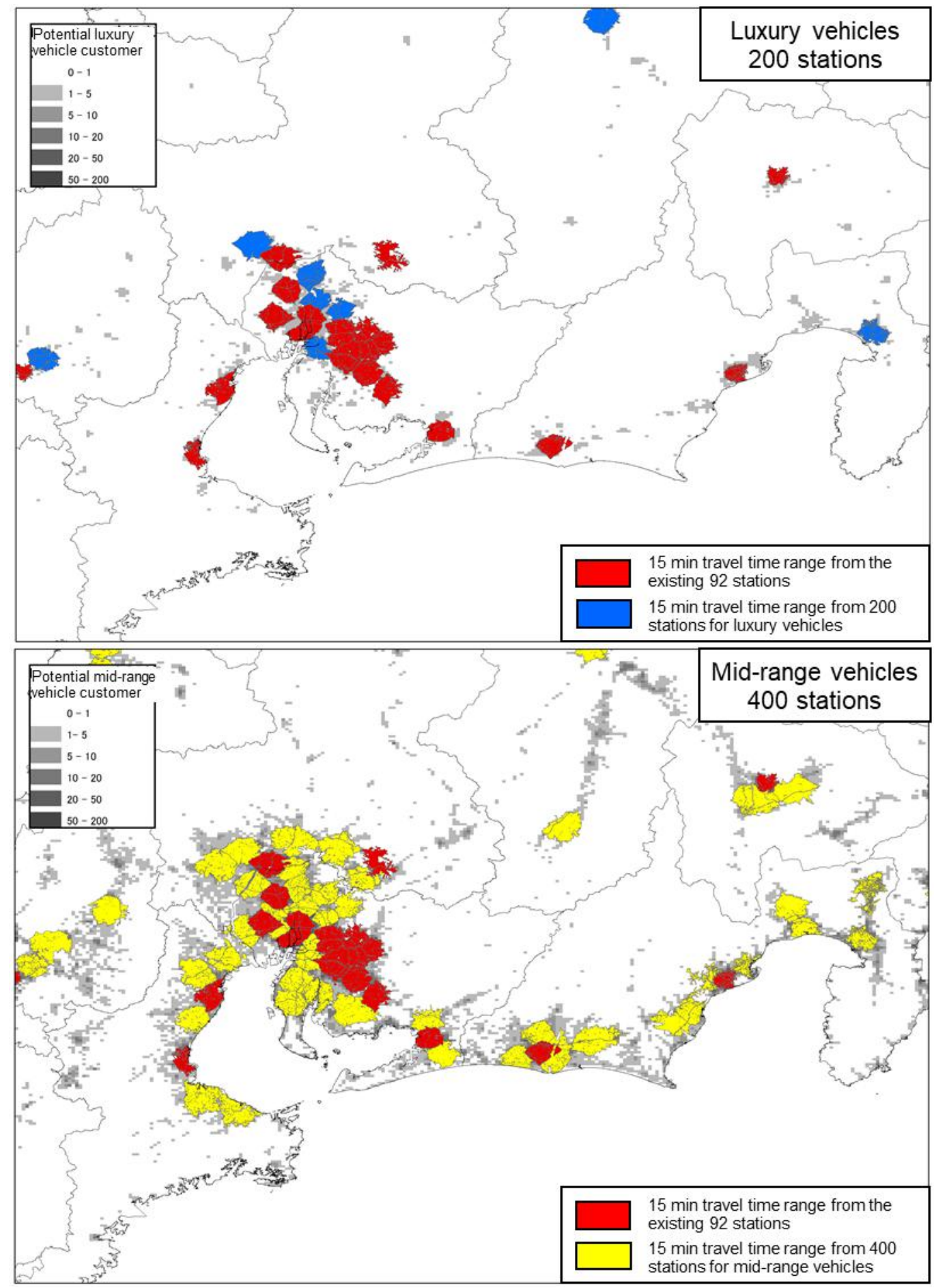

Fig. 5. Placement of 200 hydrogen refueling stations (top), 400 stations (below) in the Chukyo Metropolitan area (15-minute travel time range from the hydrogen refueling station shown) 


\section{HEET 2018}
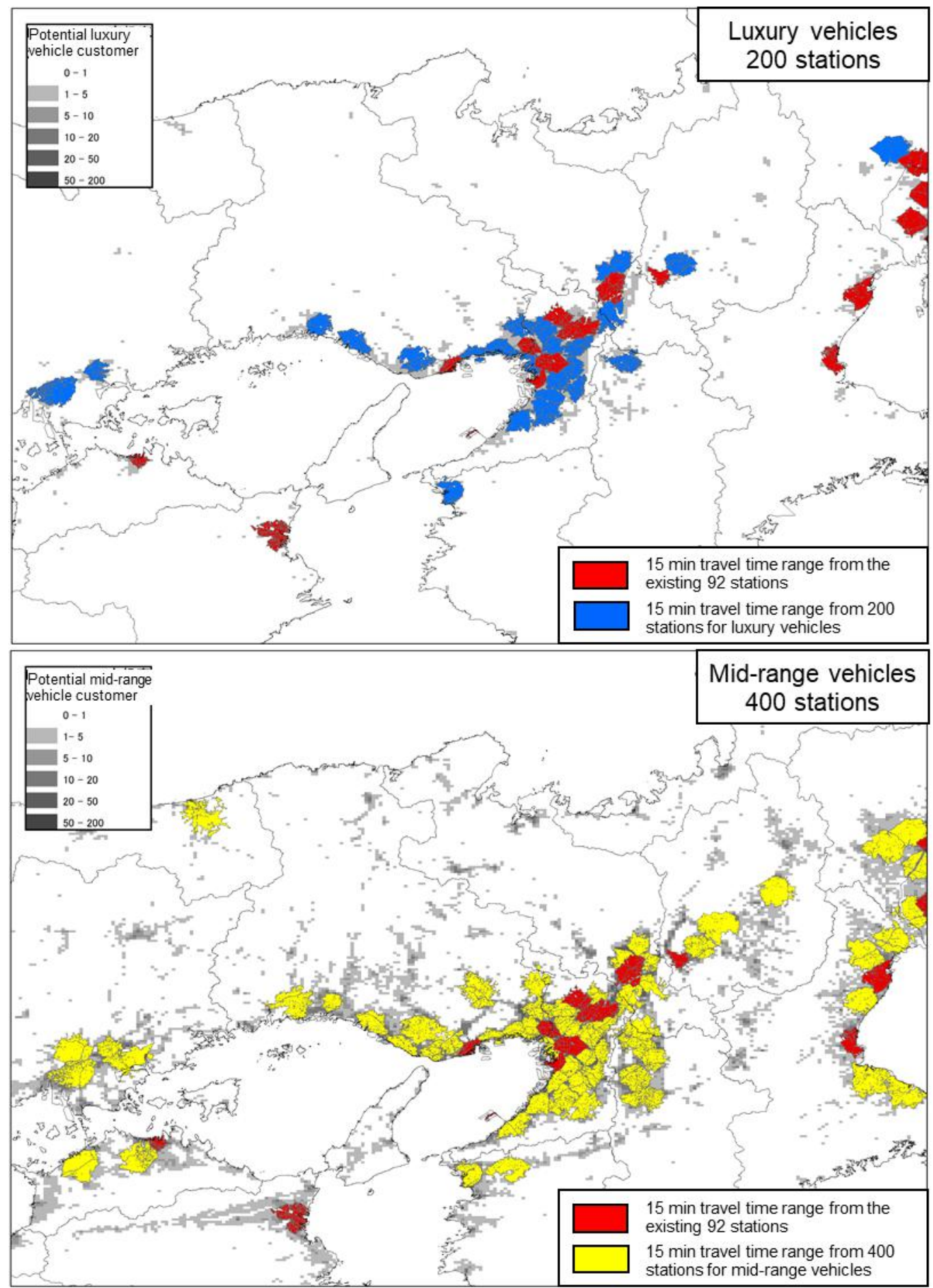

Fig. 6. Placement of 200 hydrogen refueling stations (top), 400 stations (below) in the Keihanshin Metropolitan area (15-minute travel time range from the hydrogen refueling station shown) 


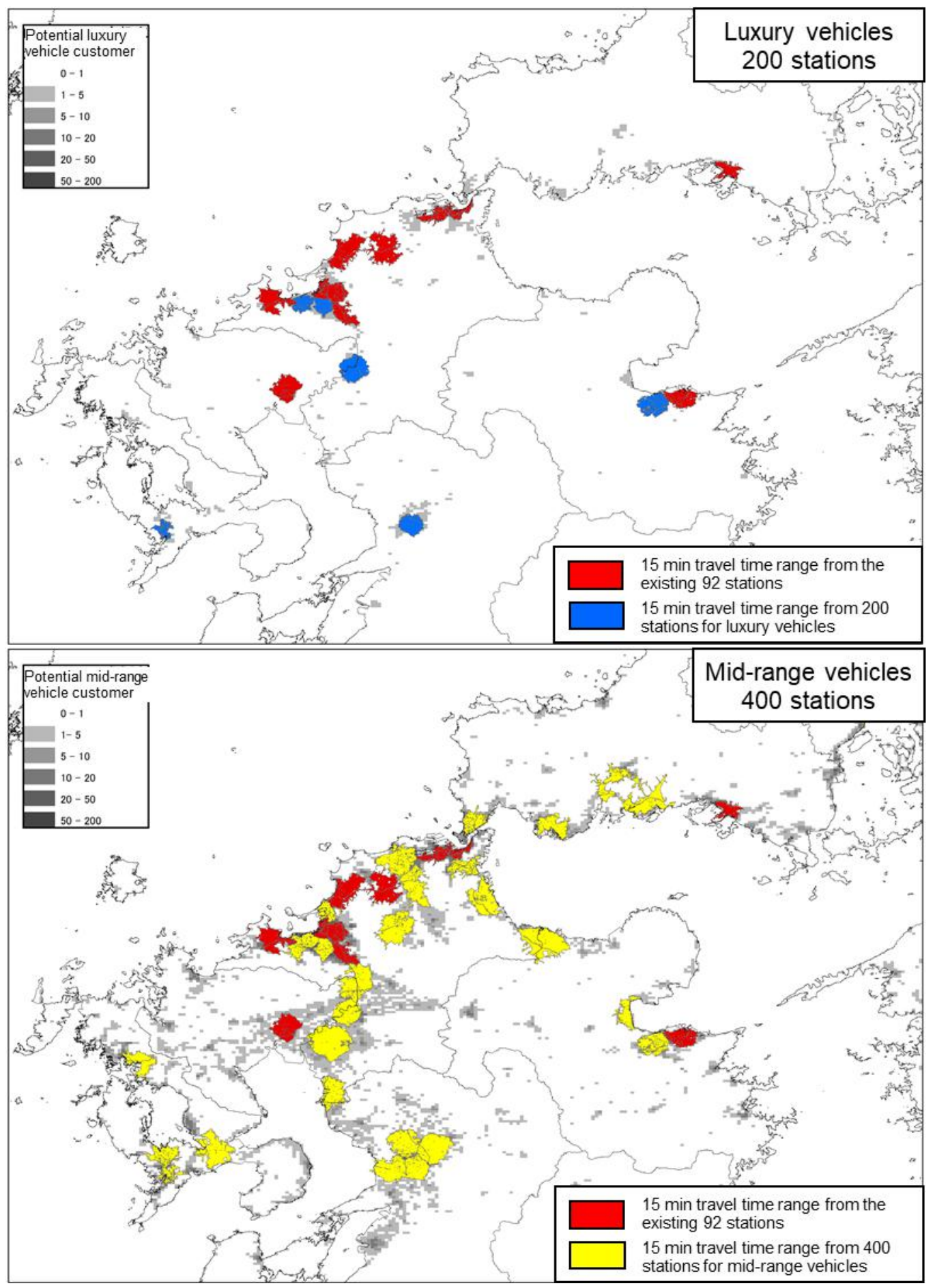

Fig. 7. Placement of 200 hydrogen refueling stations (top), 400 stations (below) in the Fukuoka Metropolitan area (15-minute travel time radius from the hydrogen refueling station shown) 


\subsection{Coverage of potential customers as a result of location allocation}

The objective of p-median is not to maximize the coverage of potential customers but to minimize the sum of weighted distance from potential customers to the stations being located. However, the coverage of potential demands and population are often discussed in locating hydrogen stations. The coverage of potential demands is thus also investigated in this study. The coverage was defined as the percentage of potential FCV buyers located within 15 minutes driving rage from any of the identified hydrogen stations. 15 minutes seems the longest distance that at least some portion of people can accept according to the social survey. As previously mentioned in Section 1.2.1, it is ideal that identified stations are located in areas convenient for individual users. As a reference, $85 \%$ of residences in Japan are located within three (3) minutes driving distance from the closest petrol station while $90 \%, 95 \%$ and $99 \%$ of them are located within 4-min, 5-min, 10-min driving distance [14]. P-median analyses were conducted to calculate the coverages of 1) potential luxury car buyers; 2) middle-class vehicle buyers; 3) the entire population; and 4) registered vehicles, for each of the 100, 200, 300 and 400 station allocations (including the 92 existing stations). The results are presented in Figures 8 to 12. In this calculation, the following definitions were applied:

The result indicated that the rate of increase in potential demand coverage became smaller for both the potential luxury car buyers and middle-class vehicle buyers as the number of hydrogen station increased in urban areas. This tendency is especially obvious in the Tokyo Metropolitan Area and for potential middle-class vehicle buyers. This is because p-median location problems tend to prefer locating facilities in regional centers rather than suburbs surrounding metropolitan areas to increase the demand coverage more effectively. While the coverage rate of the potential FCV demand is around $60 \%$ at the national level, it exceeds 70 to 80 percent when limited to urban areas for the 400 station allocation. Preference is thus likely to be given to urban areas in hydrogen facility placement.

The coverage of potential luxury vehicle buyers is about five to ten percent higher than the population coverage both nationwide and in all four metropolitan areas. On the other hand, the coverage of potential middle-class vehicle buyers is similar to the population coverage. This is due to the distribution of potential middle-class vehicle buyers which is approximately the same as the population distribution in Japan. However, the number of vehicles owned per person increases in rural areas in general. The coverage of registered vehicles is thus lower than the population coverage when more hydrogen stations are to be deployed in urban areas at an early stage. Yet, those coverages are similar in the Chukyo Metropolitan Area and the Fukuoka Metropolitan Area where the population distributions overlap with the distribution of registered vehicles. Therefore, more hydrogen stations will be required in suburbia of urban areas where vehicle holding ratios tend to be low, if the facility locations are determined based on the existing registered vehicle distribution. With regard to regional cities and other rural areas, most of the demand is likely to be covered by targeting potential middle-class vehicle buyers, as the distributions of population, registered vehicles and potential middle-class vehicle buyers are also similar in those areas. 

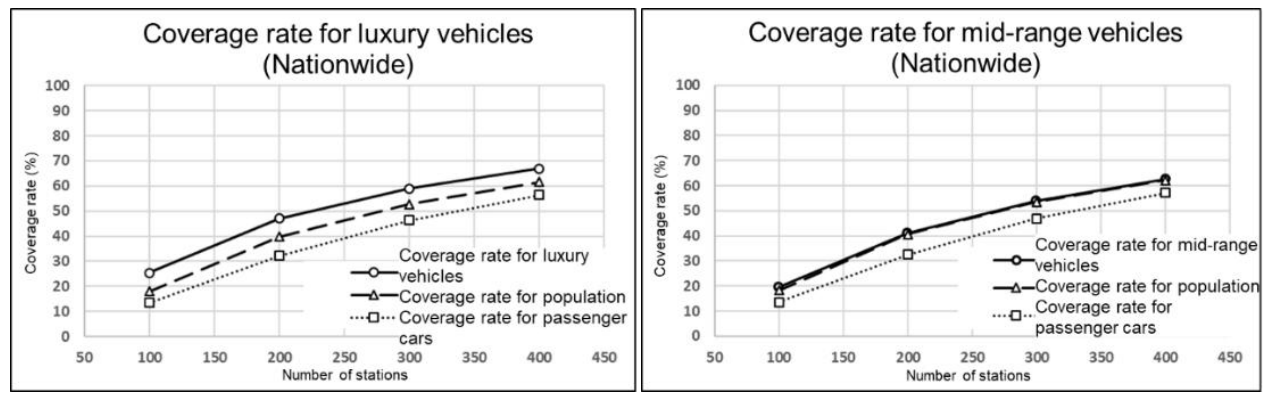

Fig. 8. National hydrogen refueling station potential coverage rate for luxury vehicles (left) and mid-range vehicles (right) (15-minute distance to hydrogen refueling station)
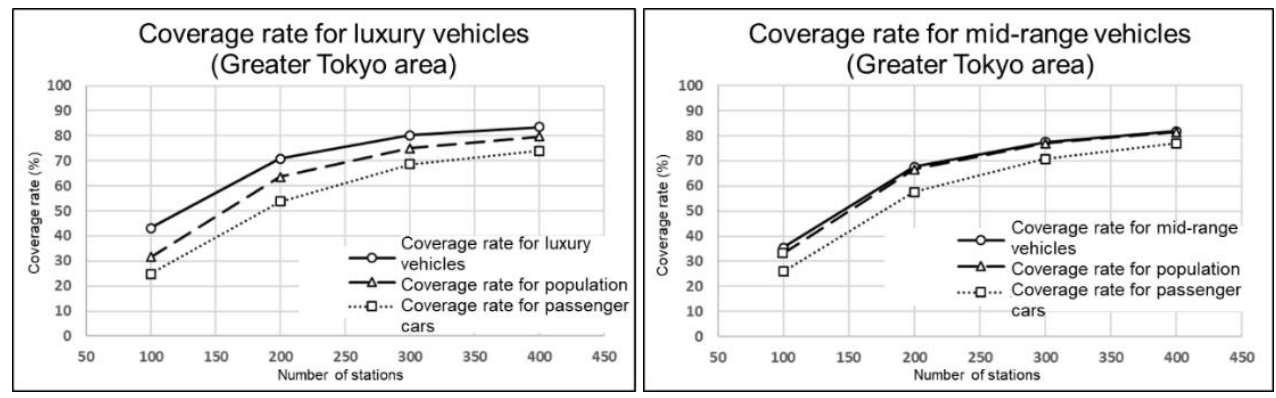

Fig. 9. Hydrogen refueling station potential coverage rate for luxury vehicles (left) and mid-range vehicles (right) in the Greater Tokyo area (15-minute distance to hydrogen refueling station)
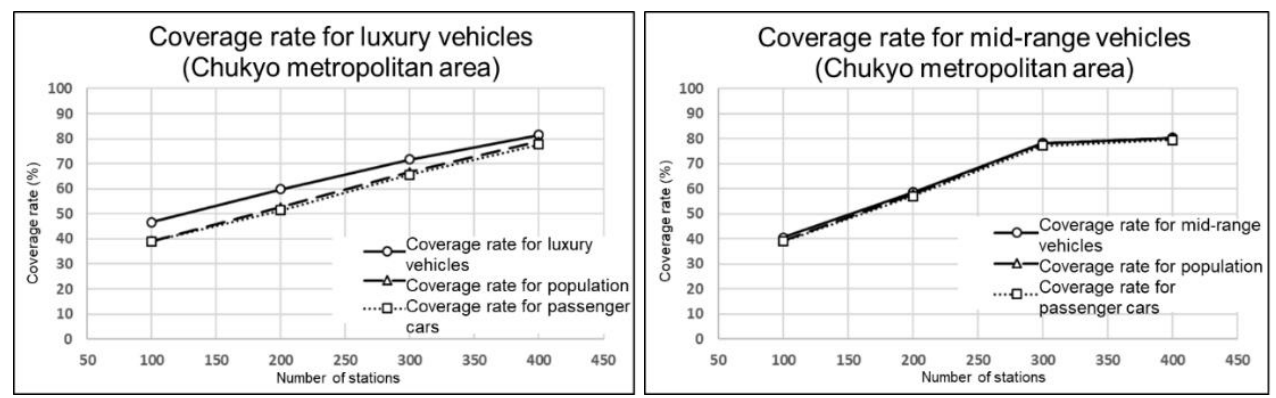

Fig. 10. Hydrogen refueling station potential coverage rate for luxury vehicles (left) and mid-range vehicles (right) in the Chukyo metropolitan area (15-minute distance to hydrogen refueling station) 


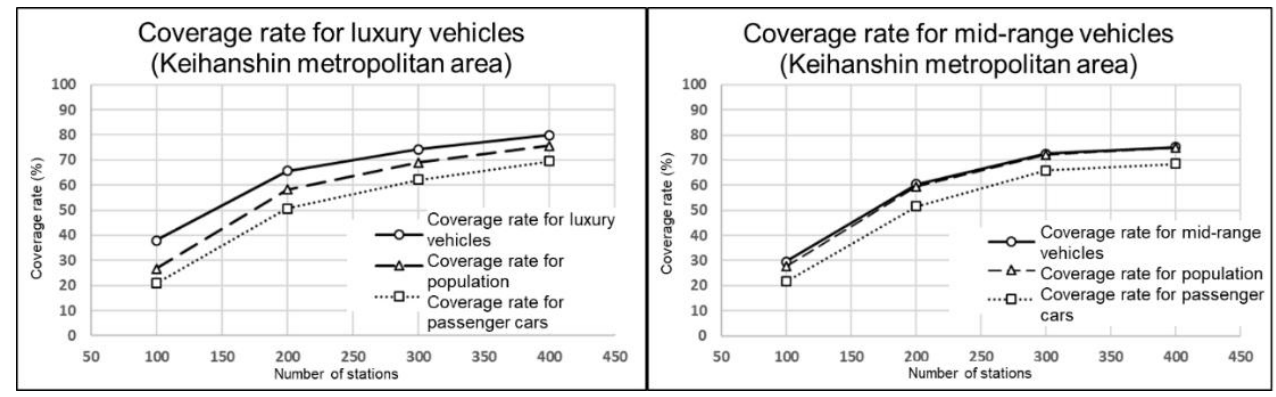

Fig. 11. Hydrogen refueling station potential coverage rate for luxury vehicles (left) and mid-range vehicles (right) in the Keihanshin metropolitan area (15-minute distance to hydrogen refueling station)
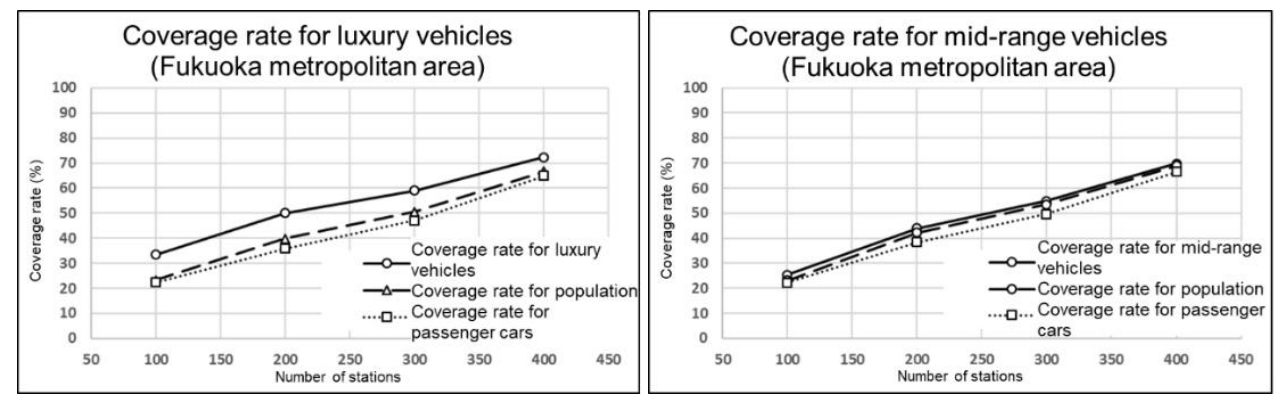

Fig. 12. Hydrogen refueling station potential coverage rate for luxury vehicles (left) and mid-range vehicles (right) in the Fukuoka metropolitan area (15-minute distance to hydrogen refueling station)

\section{Conclusion}

Hydrogen station deployment needs to be progressed in response to the introduction of fuel cell vehicles (FCVs) in the commercial market. Since resources allocated to deployment are limited for either private companies who wish to install stations and governments, efficient station allocation should be cognizant of serving potential customers. Based on literature review, results of a social survey and data analysis, p-median is chosen to find the optimum locations of hydrogen stations. Location and amount of potential demand of FCV's in the early stage of deployment is estimated by a regression model. The results of GIS analysis using p-median for both 2020 and 2025 indicated that hydrogen stations should be spread across the country to capture potential FCV customers effectively and to promote FCV deployment. The map resulting from the GIS analysis shows 94 percent prefectural capital cities are covered by the placement of the 200-stations by 2020 and fully covered by the 400 -station allocation of 2025, implying the importance of covering regional hub cities (such as prefectural capital cities) as well as metropolises. The coverage rate of the potential FCV demand is around $60 \%$ at the national level, it exceeds 70 to 80 percent when limited to urban areas for the 400 station allocation. The geographical tendency of station locations allocated by the developed methodology provides a guide for location of hydrogen stations. 


\section{References}

1. Council for a Strategy for Hydrogen and Fuel Cells, Revised Version of the Strategic Roadmap for Hydrogen and Fuel Cells [cited 2016 December 22]. Available from: http://www.meti.go.jp/press/2015/03/20160322009/20160322009-c.pdf (2016)

2. L. Cooper, Oper. Res. 11, 331-343 (1963)

3. M. A. Nicholas, S. L. Handy, D. Sperling, Transp. Res. Rec. 1880, 126-134 (2004)

4. M. A. Nicholas, J. Ogden, Transp. Res. Rec. 1983, 121-128 (2006)

5. Z. Lin, J. Ogden, Y. Fan, C. Chen, Int. J. Hydrogen. Energy. 33, 3096-3101 (2008)

6. M. J. Hodgson, Geogr. Anal. 22, 270-279 (1990)

7. M. Melendez, A. Milbrandt, Paper presented at the National Hydrogen Association Annual Hydrogen Conference 2005, Washington, D.C., the United States (2005)

8. M. A. Nicholas, J. Transp. Geogr. 18, 738-749 (2010)

9. S. Lim, M. Kuby, Eur. J. Oper. Res. 204, 51-61 (2010)

10. E. M. Rogers, Diffusion of innovations, 5th edition (Free Press, New York, 2003)

11. T. A. Feo, M. G. Resende, J. Glob. Optim. 6, 109-133 (1995)

12. M. B. Teitz, P. Bart, Oper. Res. 16, 955-961 (1968)

13. M. Boudia, M. A. O. Louly, C. Prins, Comput. Oper. Res. 34, 3402-3419 (2007)

14. S. Kimura, Kyushu university doctor thesis (2010) 